\title{
In Situ Test of Grouting Reinforcement for Water-Enriched Sandy Gravel Ground in River Floodplain
}

\author{
Jinxing Lai, Zhihua Feng, Junling Qiu, Jianxun Chen, and Haobo Fan \\ School of Highway, Chang'an University, Xian 710064, China \\ Correspondence should be addressed to Jinxing Lai; 373159626@qq.com and Junling Qiu; 870133597@qq.com
}

Received 23 March 2016; Revised 5 June 2016; Accepted 28 June 2016

Academic Editor: Juan J. Del Coz Díaz

Copyright ( 2016 Jinxing Lai et al. This is an open access article distributed under the Creative Commons Attribution License, which permits unrestricted use, distribution, and reproduction in any medium, provided the original work is properly cited.

\begin{abstract}
The performance of the ground treatment is always critical for a tunnel excavated in unstable stratum. Laodongnanlu Xiangjiang Tunnel (Changsha, China) across the Xiangjiang River will be constructed in a sandy gravel ground which is characterized by loose structure, extensive porosity, elevated sensitivity, poor stability, and a high groundwater table. Permeation grouting will be employed to improve the bearing capacity and mitigate groundwater movement into the excavation. In order to seek suitable injection parameters and grouting method, a field trial of vertical grouting was conducted in the sandy gravel stratum in river floodplain. A series of tests focusing on grout material, grouting sequence of boreholes, injection pressure, and grouting volume were performed to improve the sandy gravel mass strength and reduce water permeability. The examination of the results obtained during water pressure testing and core drilling on completion of the grouting trial successfully demonstrated that the specified injection criteria had led to an expected effect. Grouting control method of this saturated sandy gravel stratum was concluded after the test, which would contribute to the future pregrouting work during the tunnelling.
\end{abstract}

\section{Introduction}

Civil engineering designed in natural ground or stratum often encounters soft, broken, or loose strata, in which effective reinforcement is necessary when the ground bearing capacity, strength, and permeability cannot meet the requirements. A universal and effective method for ground treatment is grouting $[1,2]$, which is initially invented in France during the 19th century and gradually utilized to improve soil/rock quality along with the invention of cement grout. In the 20th century, grouting technology has been widely applied to dam waterproofing, treatment of weak strata, and reinforcement of tunnel surrounding rock. Different grouting methodologies, including permeation grouting, jet grouting, compaction grouting, and fracture grouting, are applicable for different geotechnical situations. Compared with other stratum reinforcement methods such as dynamic compaction, drainage consolidation method, and vibration compaction, grouting is superior in flexibility, equipment design, efficient application, and less overall strata disturbance [3]. Grout equipment configuration and construction methods have been gradually improved and become much more sophisticated [4-10].
Grouting reinforcement may occur in rock formation, general soil stratum, and sandy gravel stratum. Grouting in the rock strata penetrates cracks for directional filling, providing reinforcement and water plugging, which has been widely developed in engineering application. With good homogeneity in soil strata, the ground strength can be easily improved by grouting methods and many relevant studies have been conducted on the soil strata grouting [11-14]. Generally, permeation grouting is applied to reinforce sandy gravel stratum, in which the grout can easily diffuse and is difficult to control. The sandy gravel stratum is a type of quaternary accumulation consisting of fine sand, gravel, pebble, and boulders, with a loose structure, poor cemented performance, high porosity, elevated sensitivity, and richness in groundwater sometimes. And grouting is the main way to improve the stratum strength $[15,16]$.

Dano and Tsukamoto et al. $[17,18]$ studied the reinforcement mechanism and mechanical variation law of grouted sands through laboratory testing; Yang and Yu et al. [19, 20] conducted a laboratory grouting test in typical sandy pebble, regressing some equations about the relations of diffusion 


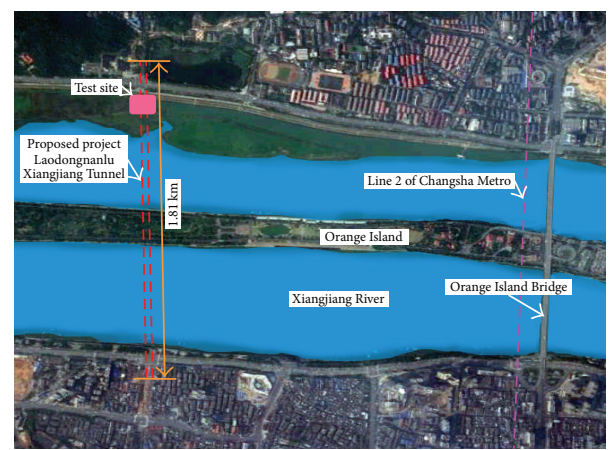

FIGURE 1: The aerial view of project place.

radius, injection pressure, and grouting parameters. Song and Bezuijen et al. [21-24] made a research related to shield tunnelling through gravel stratum and an effective grouting scheme for stabilizing stratum and reducing grout settlement was carried out. Teng and Zhang [25] fabricated new grout materials with the ability to uniformly diffuse as a columnar shape. However, those researches are usually focused on laboratory experiment and the small local scope reinforcement of shield tunnel; few studies have been conducted on grouting parameters and control methods in natural water-enriched sandy gravel stratum. An in situ test of vertical grouting in the typical river floodplain sandy gravel strata was designed to explore suitable grouting parameters and control rules, which will guide the excavation of the underwater tunnel project of Laodongnanlu Xiangjiang Tunnel.

\section{Engineering Overview}

2.1. Tunnel Situations. Laodongnanlu Xiangjiang Tunnel, designed as an important urban road connecting the Yuelu District and the Tianxin District, will cross the Xiangjiang River and the Orange Islands according to the urban planning of Changsha City. The tunnel is designed to be an urban trunk road with two independent tunnel chambers at an average distance of $35 \mathrm{~m}$, a scale of 4-lane double-way, and $4.01 \mathrm{~km}$ length. Design speed is $50 \mathrm{~km} / \mathrm{h}$ and the maximum longitudinal slope is $5.5 \%$. The river is divided into 2 branches at the site with a width of $1.3 \mathrm{~km}$ and a depth of $8.5 \mathrm{~m}$ (Figure 1). Geological investigation indicated that this site features complicate stratum structure with exceptionally diverse quaternary strata [26]. The underlying bedrock contains Cretaceous system conglomerate and Devonian system dolomite with relatively stable contact faces. Overlying strata mainly consist of the floodplain accumulation horizon and terrace with a thickness of $9-40 \mathrm{~m}$. The floodplain at the west bank is obviously thick. The unconsolidated formation of quaternary system consists of plain fill, muddy silty clay, fine sand, sandy gravel, pebble, and so forth, while the grade of surrounding rock preliminarily planned for tunnel installation is nearly all $\mathrm{V}$ and IV. Figure 2 provides a geological section [27].

2.2. Characterizations of Sandy Gravel Stratum. This floodplain sandy gravel stratum with nearly no cement material,

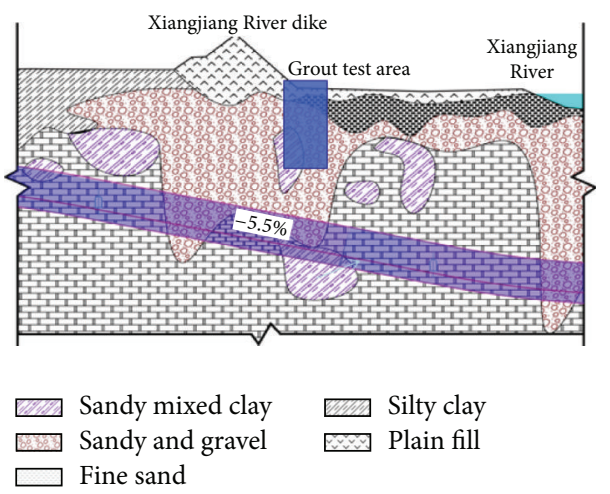

FIGURE 2: West part longitudinal geological profile of north line (vertical scale 1:500 and horizontal scale 1:1000) [26].

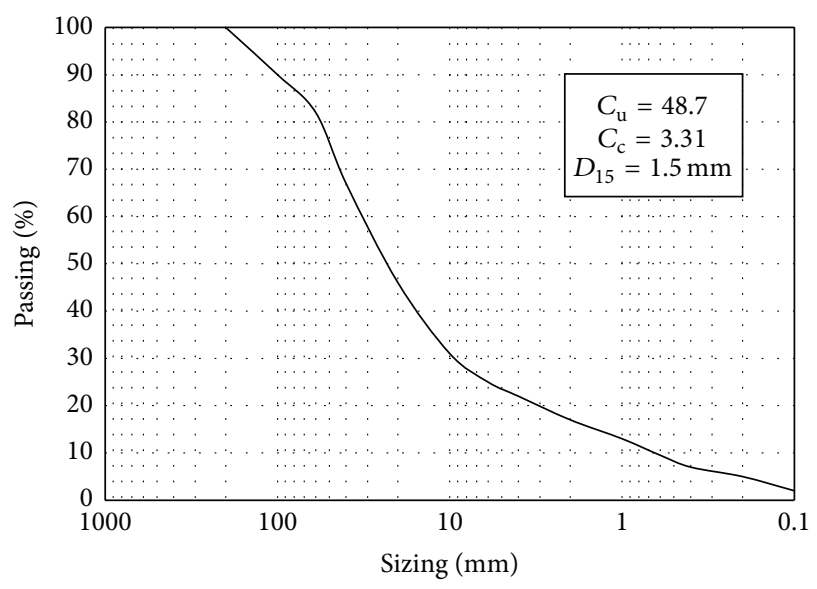

FIGURE 3: Grading curve of typical core sample.

however, is quite different from the normal gravel strata in related codes. Grain diameter composition is mainly 5$60 \mathrm{~mm}$ gravel and filled with $0.5-2 \mathrm{~mm}$ in the gap. There are almost no complete core samples in the geological investigation. Grading curve and typical core sample are shown in Figures 3 and 4 . This sandy gravel stratum is caused by a combination of alluvial effects and diluvial actions and is widely distributed in the west bank with a thickness varying from 7 to $28 \mathrm{~m}$, contacting bedrock at the bottom. The ground permeability coefficient is $2.3 \times 10^{-4} \mathrm{~m} / \mathrm{s}$ and its groundwater connects with the river water. The tunnel section with a length of $220 \mathrm{~m}$ will be constructed in sandy gravel stratum by drilling and blasting method, which should be well treated before excavation in consideration of the risks of sudden geological disasters such as water ingress and collapse.

\section{Experimental Design and Implementation}

3.1. Test Aims. Because of the safety issues associated with tunnelling crews working in unstable ground conditions, the performance of the ground treatment is critical. The pregrouting is an effective way to improve the stability and reduce water permeability prior to excavation, but specific 


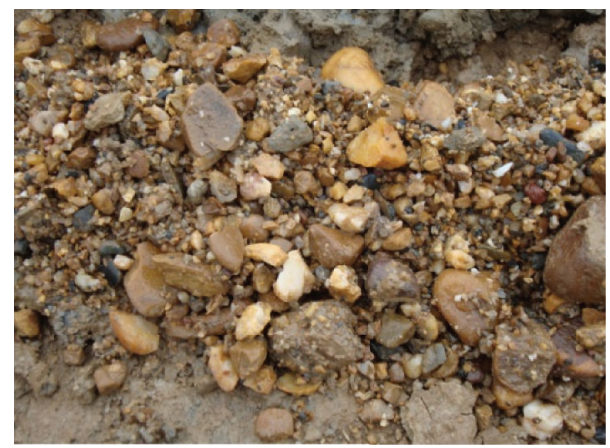

FIGURE 4: Core sample of sandy and gravel stratum.

injection parameters and grouting sequence must be determined first. To obtain the grouting parameters in sandy gravel ground, a test could always work. For this purpose, in situ testing is necessary to determine the required grouting parameters and the control technology for this ground. A program of field trials was designed to address the following:

(1) Selecting the appropriate grout for the ground conditions.

(2) The volume of grout required per $\mathrm{m}^{3}$ of treated ground.

(3) The grouting volume and grouting pressure in the designed diffusion radius.

(4) Injection sequence for the grouting boreholes in the zone.

The treated ground should meet the general requirements of engineering construction; the ground bearing capacity must meet the design requirements of over $400 \mathrm{kPa}$; meanwhile the permeability coefficient of stratum should be lower than $1 \times 10^{-6} \mathrm{~m} / \mathrm{s}$ [28-30]. Vertical grouting was applied in the grouting test, and an evaluation of treated ground obtained by core drilling and water testing will be provided after completion.

3.2. Test Site and Injection Methodology. The test site is located at the west bank floodplain of Xiangjiang River, directly above the north-line tunnel position of XK1 +180 , and its plane position and section position are shown in Figures 1 and 2 . The field is covered with typical sandy gravel except the shallow upper layer. This site is within close proximity to the flood control dike, offering a convenient and rapid path for material transport and evacuation in the event of a flood. A platform (Figure 5), with a plane size of $16 \mathrm{~m}$ $\times 14 \mathrm{~m}$, was built on the original ground surface of the test site to prevent potential inundation resulting from rising river levels since the rainy season was coming when the grouting work started. High grouting pressure may lead to stratum expansion and dam structure damage, so deformation monitoring was performed during grouting. There are totally 85 boreholes with a depth of $24 \mathrm{~m}$ and a diameter of $91 \mathrm{~mm}$.

All the boreholes were spilt into 2 groups according to their locations, a peripheral group with 68 boreholes and an

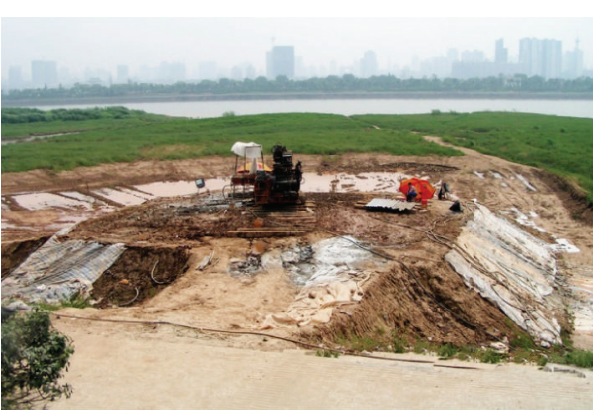

FIGURE 5: The platform for grouting work.

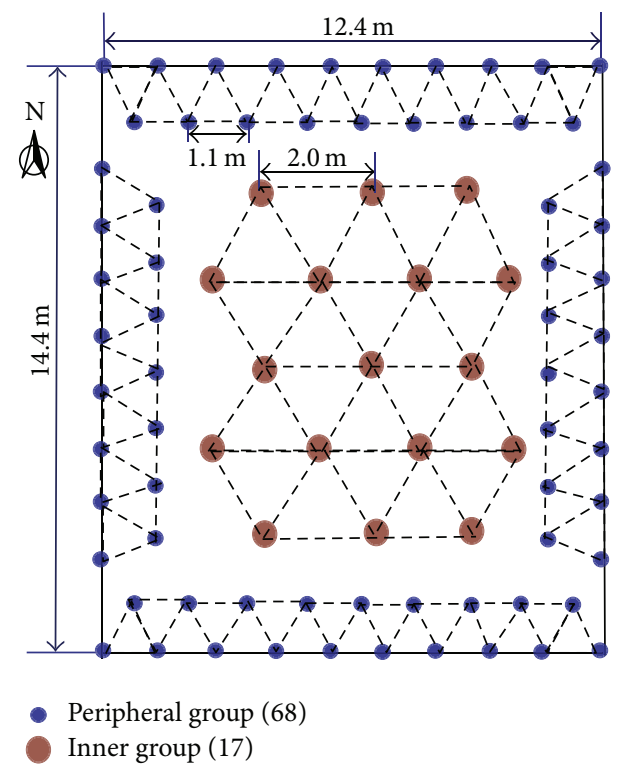

FIGURE 6: Distribution of boreholes.

inner group with 17 boreholes, distributed following equilateral triangles (Figure 6). The peripheral group boreholes would be injected first to compose a reinforced curtain, and then the inner group boreholes would be injected to form a unified entity.

The sleeve valve tube grouting method has been extensively applied in loose stratum reinforcement [31-34] and is also adopted in this test. The sleeve valve tube is comprised of sleeve tube and core tube. The sleeve tube is divided into 50 sections, and the core tube will be lifted up from the bottom of sleeve tube until the ground surface, drawing back when the section is injected into target grout volume, and this cycle will be repeated until the whole sections of a borehole are injected. Figure 8 shows the process and details. Hole collapse happened frequently at the beginning because of the loose structure of sandy gravel, which was solved after taking the Italy Casa C6 drill equipment. The grouting pump type was KBY-50/70, which could mix two kinds of slurry.

3.3. The Optimum Grout Mix Formulation. Cement slurry, composite slurry, cement, and sodium silicate mixed slurry are often employed to grout the sandy and gravel ground. 
TABLE 1: Experiment results of grout with different mixture ratio.

\begin{tabular}{lcccc}
\hline $\begin{array}{l}\text { Number } \\
\text { (mass ratio) }\end{array}$ & $\begin{array}{c}\text { Water cement ratio } \\
\text { water glass (Be) }\end{array}$ & $\begin{array}{c}\text { Average gelation } \\
\text { time (s) }\end{array}$ & Opinion \\
\hline 1 & & 45 & 74.4 & Not applicable \\
2 & $\mathrm{~W}: \mathrm{C}=1: 1$ & 40 & 62.5 & Applicable \\
3 & & 35 & 56 & Applicable \\
4 & & 30 & 47.5 & Applicable \\
\hline 5 & & 45 & 52.6 & Applicable \\
6 & $\mathrm{~W}: \mathrm{C}=0.8: 1$ & 40 & 46.5 & Applicable \\
7 & & 35 & 41.1 & Not applicable \\
8 & & 30 & 36.2 & Not applicable \\
\hline
\end{tabular}

However, the grout should have a good ability of dispersion resistance and a short gelation time because the sandy gravel stratum in the test field is rich in groundwater. Cement slurry features a high stone rate but a long gelation time and poor antidispersion properties. Composite slurry possesses high viscosity but the configuration processes are complex, and it is expensive. Cement and sodium silicate mixed grout is cost saving and satisfies operating requirements of viscosity, gelation time, and good consolidation strength; thus it is selected in this field test based on the overall consideration of factors and the grout optimum mix formulation will be determined in the laboratory experiments.

A grout gelation time with a range of $45-70 \mathrm{~s}$ is appropriate based on the theory that gelation occurs when slurry diffuses to the expected position [34]. Raw materials are P42.5\# composite Portland cement, 51 Be sodium silicate (diluted to different concentrations later, $M=1.7-3.1$ ), and drinking water. Material proportion is as follows: cement-towater quality ratio $\mathrm{W}: \mathrm{C}=0.8: 1-1: 1$ and cement-to-sodium silicate volume ratio $C: S=1: 1$. There were 8 groups in experiment with different mix formulation being conducted and the gelation time of each group would be obtained after repeating the same experiment 3 times. Experimental results were displayed in Table 1.

The experiment demonstrated that reaction speed increases with the decrease of water-cement ratio and the decrease of water glass density. Several groups achieved the specified criteria and group number 3 was selected for the field trial due to its lower cost. Mix proportions in the remaining groups were stored for reserve purposes.

\subsection{Grouting Calculation}

3.4.1. Grout Volume Calculation. Permeation grouting was adopted to fill gaps of particles with slurry, cementing the particles to a whole entity without damaging the original arrangement conditions [35-37]. Permeation grouting has a series of calculation formulas; one of them is the Maag equation for the globe symmetry diffusion [35], but they are hardly helpful in practical engineering. The injection parameters are usually selected on the basis of empirical formulas or previous experience in China, and one empirical formula [36] is employed to estimate the target grout volume:

$$
Q=K \alpha \beta V
$$

where $Q$ is grout volume $\left(\mathrm{m}^{3}\right), K$ is shrinkage factor whose value is in the range 1.1 1.3 in sandy gravel ground, $\alpha$ is formation porosity (\%), $\beta$ is filling rate whose value is between $70 \%$ and $90 \%$ in sandy gravel ground, and $V$ is the treated ground volume $\left(\mathrm{m}^{3}\right)$.

Considering all factors in the field test, $K$ is $1.1, \alpha$ is 0.3 , and $\beta$ is 0.8 . To realize the reinforcement of entire designed test zone, the target grout volume is

$$
Q=K \alpha \beta V=1.1 \times 0.3 \times 0.8 \times 3789 \mathrm{~m}^{3}=1000.3 \mathrm{~m}^{3}
$$

3.4.2. Injection Pressure. The hydrostatic pressure, pipe friction loss pressure, pore resistance, and so forth should be considered in the grouting pressure setting in this trial. No accurate calculation results can be used, but an empirical formula is available for sandy gravel grouting pressure as follows [38]:

$$
P=P_{W}+P_{L}+(0.5 \sim 1 \mathrm{MPa}),
$$

where $P_{W}$ is hydrostatic pressure, $P_{L}$ is pipe friction loss pressure along grout pipe, and $(0.5-1 \mathrm{MPa})$ are the other combined pressures.

In this test, $P_{W}$ was $0.2 \mathrm{MPa}, P_{L}$ was $0.2 \mathrm{MPa}$, and grouting pressure was between 0.9 and $1.4 \mathrm{MPa}$, so the grouting pressure between 0.5 and $1.5 \mathrm{MPa}$ would be adopted. The spacing of holes is fixed before grouting, so the grouting pressure and grouting volume would be adjusted to achieve more uniform spreading around borehole. Preliminary grouting parameters are outlined in Table 2.

\subsection{In Situ Grouting Test}

3.5.1. The Injection of Peripheral Group. Prior to the formal grouting, all the boreholes were named as shown in Figure 9. Several boreholes were injected first according to the designed parameters. The injection pressure and grouting volume for each section were adjusted to the site conditions and all information was recorded to help find the best grouting control method.

Four boreholes of peripheral group were injected first, following a sequence of $\mathrm{C} 1 \rightarrow \mathrm{A} 1 \rightarrow \mathrm{C} 2 \rightarrow \mathrm{C} 11$. In different sections of a borehole, an increasing grouting pressure and a constant injection pressure had been tried independently. The adjacent holes were selected as observation points during 
TABLE 2: Preliminary grouting parameters.

\begin{tabular}{lcc}
\hline Number & Parameters name & Value \\
\hline 1 & Diffusion diameter & $1.6 \mathrm{~m}\left(D_{1}\right), 2.6 \mathrm{~m}\left(D_{2}\right)$ \\
2 & Depth of treated ground & $4 \sim 24 \mathrm{~m}$ \\
3 & Reinforced length & $20 \mathrm{~m}$ \\
4 & Grout gelation time & $56 \mathrm{~s}$ \\
5 & Grout pressure & $0.5-1.5 \mathrm{MPa}$ \\
6 & Grout volume of each section of peripheral group holes & $212 \mathrm{~L}$ \\
7 & Grout volume of each section of inner group holes & $560 \mathrm{~L}$ \\
\hline
\end{tabular}

the grouting process. Analyzing data collected during grouting, $\mathrm{C} 1$ and $\mathrm{A} 1$ had a similar process of change under two kinds of grouting pressures as shown in Figures 10(a) and 10(b), while the holes of C2 and C11 had a similar process of change under two kinds of grouting pressures as shown in Figures 11(a) and 11(b). The following results were gathered:

(1) The sandy and gravel ground can be easily injected under a low injection pressure. The grouting rate decreased with time at a constant grouting pressure.

(2) The adjacent boreholes are affected by each other. The former borehole has a greater grouting volume than the adjacent boreholes.

(3) When the grout leaking occurred frequently in the adjacent holes, the grouting pressure decreased and grouting work should be stopped. Boreholes of $\mathrm{Cl}$ and A1 have an average grouting volume of $280 \mathrm{~L}$ in each section, and boreholes of $\mathrm{C} 1$ and $\mathrm{A} 1$ have an average grouting volume of $220 \mathrm{~L}$ in each section.

(4) The time that grout diffuses to the expected position is quite different under the different grouting pressure, and time spent under constant pressure is more than 1.5-2 times as much as an increasing grouting pressure spent. Therefore, grouting at an increasing injection pressure is much more effective.

As information from the 4 boreholes, the grouting sequence should be well arranged due to the interaction effects of adjacent boreholes. Additionally, if one hole was grouted, the adjacent hole could not be injected with the same volume due to the diffusion effect from the previous holes; thus the adjacent holes of peripheral group should be injected separately. The remaining holes of peripheral group were divided into two groups: peripheral group A and peripheral group B (Figure 12), which were injected in different control orders.

Peripheral group A would be injected first at a principle of low injection pressure whose value was between 0.5 and $0.8 \mathrm{MPa}$ and a constant grout volume of $280 \mathrm{~L}$. Total grouting orders were as the following: $\mathrm{C} 1 \rightarrow \mathrm{A} 1 \rightarrow \mathrm{C} 2 \rightarrow \mathrm{C} 11 \rightarrow$ $\mathrm{A} 2 \rightarrow \mathrm{A} 4 \rightarrow \mathrm{A} 6 \rightarrow \mathrm{A} 8 \rightarrow \mathrm{B} 10 \rightarrow \mathrm{B} 12 \rightarrow \mathrm{B} 14 \rightarrow \mathrm{B} 16 \rightarrow$ $\mathrm{B} 18 \rightarrow \mathrm{B} 19 \rightarrow \mathrm{D} 8 \rightarrow \mathrm{D} 6 \rightarrow \mathrm{D} 4 \rightarrow \mathrm{D} 2 \rightarrow \mathrm{D} 1 \rightarrow \mathrm{C} 10 \rightarrow$ $\mathrm{C} 8 \rightarrow \mathrm{C} 6 \rightarrow \mathrm{C} 4 \rightarrow \mathrm{C} 3$.

Peripheral group B would be started after all of the boreholes of peripheral group A were all injected. It was to be injected at a constant volume or a certain end pressure; that is, if the grout volume reached $220 \mathrm{~L}$ in every section, grouting was discontinued and the upper section was initiated and if volume had not reached $220 \mathrm{~L}$ but grouting pressure had reached $1 \mathrm{MPa}$, the grouting was also discontinued and the upper section was to be initiated. Total grouting sequence was as follows: $\mathrm{A} 9 \rightarrow \mathrm{A} 3 \rightarrow \mathrm{A} 11 \rightarrow \mathrm{A} 10 \rightarrow \mathrm{A} 5 \rightarrow \mathrm{A} 7 \rightarrow \mathrm{B} 1 \rightarrow$ $\mathrm{B} 11 \rightarrow \mathrm{B} 13 \rightarrow \mathrm{B} 15 \rightarrow \mathrm{B} 17 \rightarrow \mathrm{D} 7 \rightarrow \mathrm{D} 5 \rightarrow \mathrm{D} 3 \rightarrow \mathrm{C} 9 \rightarrow$ $\mathrm{C} 7 \rightarrow \mathrm{C} 5 \rightarrow \mathrm{A} 12 \rightarrow \mathrm{A} 13 \rightarrow \mathrm{A} 14 \rightarrow \mathrm{A} 15 \rightarrow \mathrm{B} 2 \rightarrow \mathrm{B} 3 \rightarrow$ $\mathrm{B} 4 \rightarrow \mathrm{B} 5 \rightarrow \mathrm{B} 6 \rightarrow \mathrm{B} 7 \rightarrow \mathrm{B} 8 \rightarrow \mathrm{B} 9 \rightarrow \mathrm{D} 15 \rightarrow \mathrm{D} 14 \rightarrow$ $\mathrm{D} 13 \rightarrow \mathrm{D} 12 \rightarrow \mathrm{D} 11 \rightarrow \mathrm{D} 10 \rightarrow \mathrm{D} 9 \rightarrow \mathrm{C} 19 \rightarrow \mathrm{C} 18 \rightarrow \mathrm{C} 17$ $\rightarrow \mathrm{C} 16 \rightarrow \mathrm{C} 15 \rightarrow \mathrm{C} 14 \rightarrow \mathrm{C} 13 \rightarrow \mathrm{C} 12$.

3.5.2. The Injection of Inner Group. The grouting curtain was created in the surrounding area of the site before the inner group was injected, so a high injection pressure was necessary to ensure effective filling. The typical injection process of hole E1 was recorded and the changes were displayed in Figure 13. It was obvious that the inner group had a bigger injection pressure and grouting volume than the peripheral group. These results indicated that an increasing injected pressure and a grouting volume of $400 \mathrm{~L}$ were suitable for each section. However, considering the location and time, grouting with an increasing grouting pressure and discontinuing at an end pressure of $2 \mathrm{MPa}$ was the best control method. So the rest holes of inner group were injected in the biggest end pressure of $2 \mathrm{MPa}$. Final grouting sequence was the following: E1 $\rightarrow$ $\mathrm{E} 2 \rightarrow \mathrm{E} 3 \rightarrow \mathrm{E} 4 \rightarrow \mathrm{E} 5 \rightarrow \mathrm{E} 6 \rightarrow \mathrm{E} 7 \rightarrow \mathrm{E} 8 \rightarrow \mathrm{E} 9 \rightarrow$ $\mathrm{E} 10 \rightarrow \mathrm{E} 11 \rightarrow \mathrm{E} 12 \rightarrow \mathrm{E} 13 \rightarrow \mathrm{E} 14 \rightarrow \mathrm{E} 15 \rightarrow \mathrm{E} 16 \rightarrow \mathrm{E} 17$

3.5.3. The Preliminary Summary of Grouting Work. The test was initiated on April 10 and finished on May 11, and a total of 85 holes were injected. The relative performance of grouting volume and injection pressure in different diffusion diameters was established at the beginning to facilitate effective grouting in each group. The total slurry consumption was $1085 \mathrm{~m}^{3}$, which fitted well with the computed amount. Grouting information of the 3 groups was detailed in Table 3. Peripheral group A featured a moderate grouting volume and smallest grouting pressure among 3 groups due to large porosity and loose structure of sandy gravel ground. Peripheral group B was conducted at a constant grout volume or a fixed end pressure, with the smallest average grouting amount and bigger grouting pressure than the first group. The inner group featured larger borehole spacing and a maximum hole 
TABLE 3: Grouting overview for 3 groups.

\begin{tabular}{lcccc}
\hline Group & Control principles & Specified injection criteria & Hole number & Volume of each hole $\left(\mathrm{m}^{3}\right)$ \\
\hline Peripheral group A & Constant grout volume & $280 \mathrm{~L} /$ section & 24 & 15.3 \\
Peripheral group B & Constant grout volume or pressure & $200 \mathrm{~L} /$ section or 0.8 MPa & 44 & 9.6 \\
Inner group & Fixed end pressure & $2 \mathrm{MPa}$ & 17 & 18.0 \\
\hline
\end{tabular}

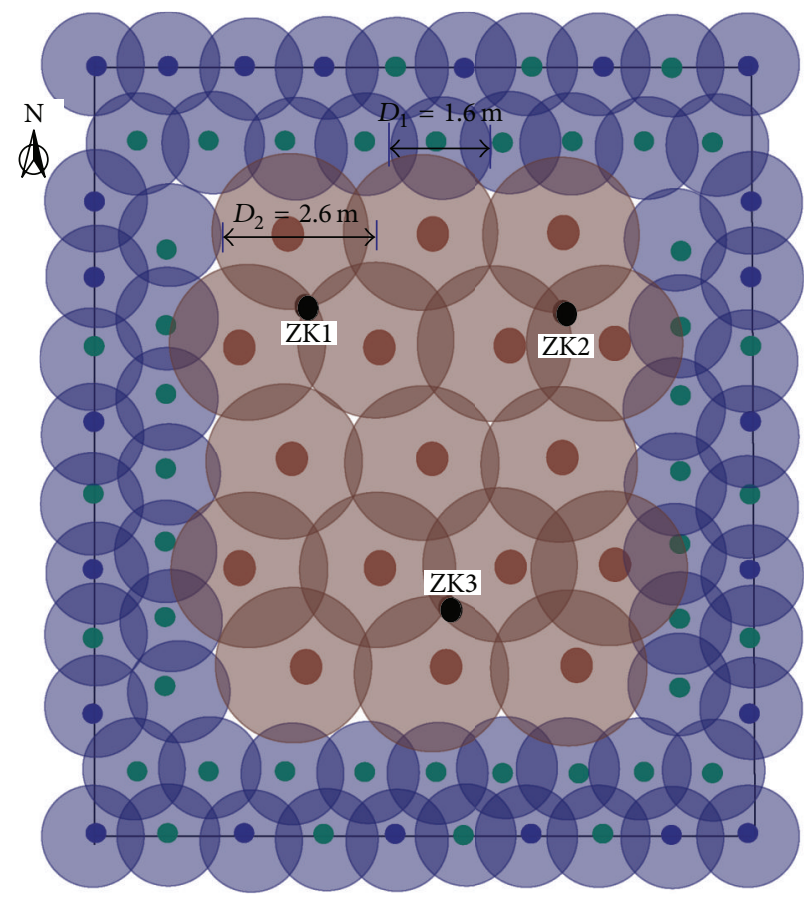

Figure 7: The designed diffusion diameter.

grouting volume under the biggest end injection pressure. Oozing slurry occurred near the end of grouting work and the platform had an obvious ground heave in the last grouted holes, which indicated that the slurry had achieved significant filling under the design pressure.

\section{Test Results Examination}

4.1. Core Boring Check. Core boring check, including core integrity rate, slurry filling rate, and core strength, was used to evaluate the treated ground. It was difficult to obtain intact core samples from the treated gravel due to the existence of large grain-sized pebbles, and core sample only allowed a qualitative evaluation by observation rather than strength test. There were 3 drill holes, located in the middle of 3 grouted holes in which place the grout is relatively difficult to reach, named ZK1, ZK2, and ZK3 (Figure 7). The ground in the test area mainly consists of sandy and gravel, little siltyfine sand. Figures 4 and 14 represent the typical core samples of sandy gravel strata and fine gravel strata prior to grouting and Figures 15 and 16 represent core samples after injection.

The structure of gravel exhibits a loose state prior to grouting, without gelled material, mainly composed of 2$4 \mathrm{~mm}$ round gravel (Figure 14). After grouting the core sample is exceptionally firm with an integrated rate over $80 \%$ (Figure 15). The typical sandy and gravel core sample displayed a wide particle size distribution and larger pebbles (Figure 4); then the rate of coring completeness reached approximately $45 \% \sim 60 \%$ with a grout filling rate of $40 \% \sim$ $45 \%$ after injection (Figure 16). These results indicated the grout diffusion radius has achieved a desired requirement and the stratum integrity and bearing capacity are significantly improved.

4.2. Water Pressure Test. An in situ permeability test is another important index to evaluate the treated ground. Water pressure testing is applied to determine the stratum permeability coefficient $k$. This test can get specific water absorption levels by forcing water to permeate the surrounding rock from the cracks in the borehole walls via a pressure pump. The calculation formula is as follows [39]:

$$
k=\frac{Q}{2 \pi L H} \lg \frac{L}{r}
$$

where $L$ is the length of test section (m), $H$ refers to the head elevation $(\mathrm{m}), r$ is the radius of borehole $(\mathrm{m})$, and $Q$ is steady flow $\left(\mathrm{m}^{3}\right)$. 


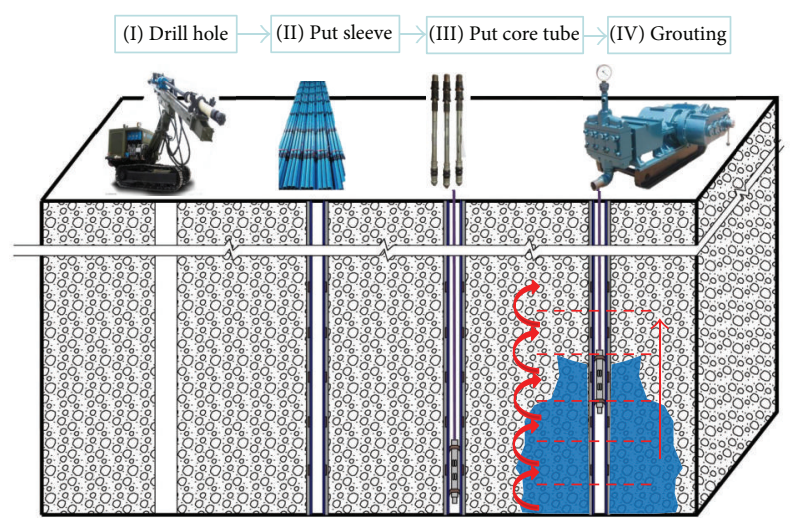

(a)

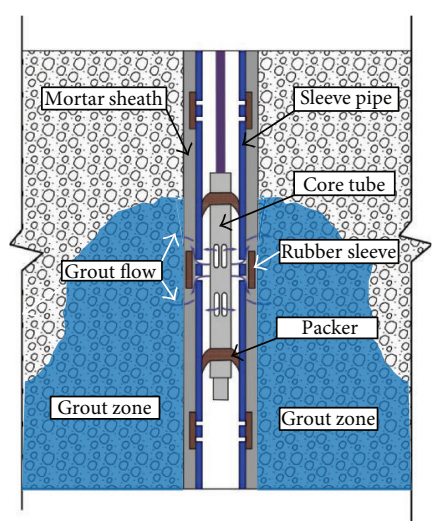

(b)

FIGURE 8: The grouting procedure of sleeve valve tube grouting method and its detailed composition.

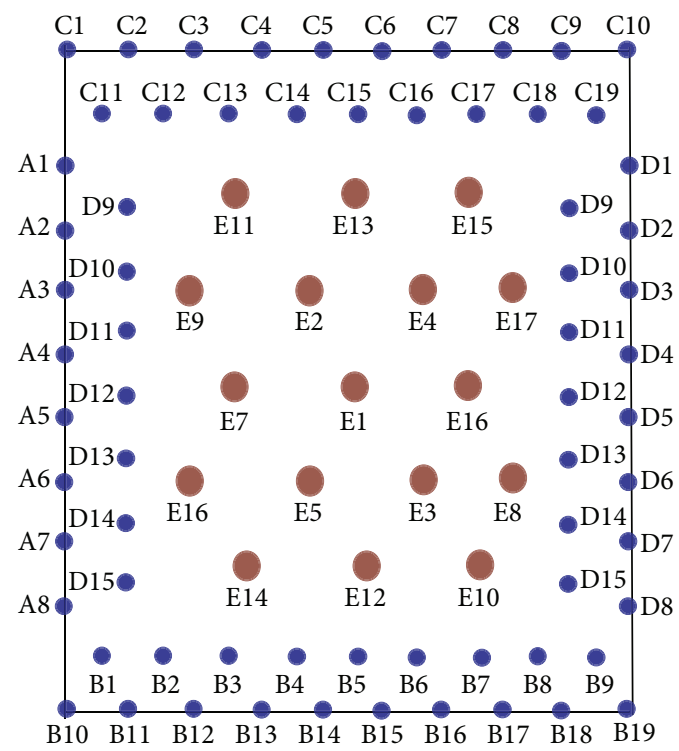

FIGURE 9: Distribution of 2 groups of boreholes.

Water pressure test was conducted at a depth of $12-22 \mathrm{~m}$. The permeability coefficient obtained was between $1.22 \times$ $10^{-8} \mathrm{~m} / \mathrm{s}$ and $5.21 \times 10^{-7} \mathrm{~m} / \mathrm{s}$ after grouting [40], which was significantly reduced and considerably lower than the specified median of $1 \times 10^{-6} \mathrm{~m} / \mathrm{s}$ for underground construction.

4.3. Monitoring for Flood Protection Dike. Improper grouting often leads to expansion of the stratum and threatens the safety of surrounding buildings [41]. Settlement monitoring of dike was arranged to avoid structural damage resulting from stratum uplift during the grouting. No obvious ground uplift was observed until the final phase, May 7-10, when the last serval holes of the inner group were being injected (Figure 17). The maximum settlement of ground surface was $+7.1 \mathrm{~mm}$ and a local crack appeared in the dike on May 8 . Things went on well after the grouting speed was slowed down in the remaining holes. Most monitoring points presented a maximum vertical settlement less than $5 \mathrm{~mm}$, which indicated that the dike just stayed in safe state.

\section{Conclusions}

The final results demonstrated that the specified injection criteria for different group holes could meet the reinforced and water ingress requirements. To summarize this in situ test of vertical grouting in typical river floodplain sandy gravel stratum, the following results are obtained:

(1) Permeation grouting method and sleeve valve pipe grouting technology can be applied to treat sandy gravel ground. The cement-sodium silicate binary slurry, with a mix grout proportion of $\mathrm{W}: \mathrm{C}$ (mass ratio) of $1: 1, \mathrm{C}: \mathrm{S}$ (volume ratio) of $1: 1, \mathrm{PC} 42.5$ cement, Baume degree of water glass $30 \mathrm{Be}$, and 


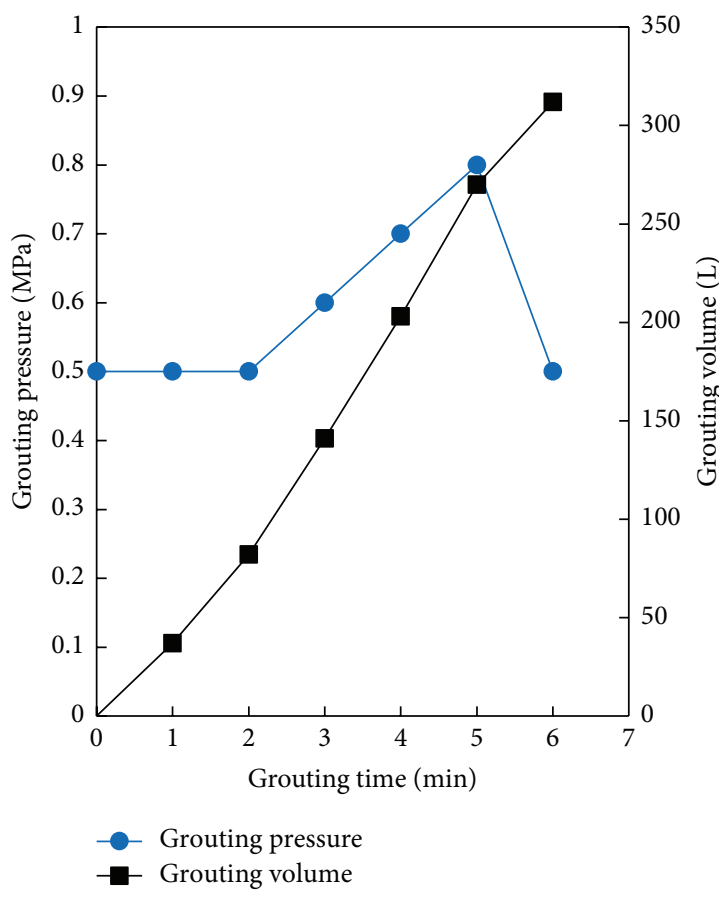

(a) Inject under an increasing grouting pressure

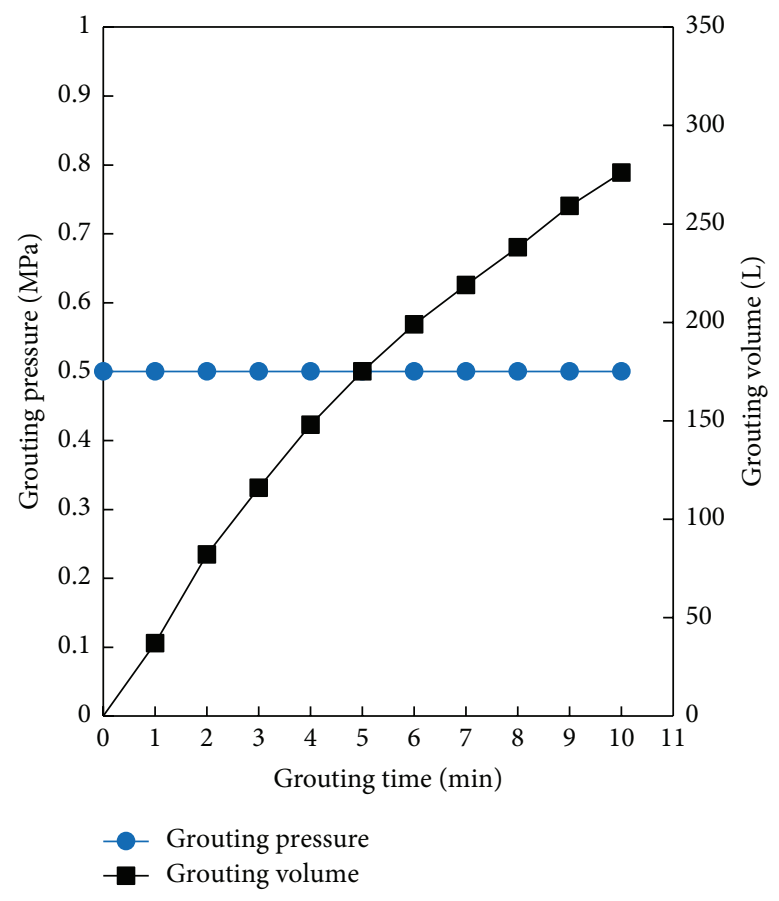

(b) Inject under a constant grouting pressure

Figure 10: The typical grouting process of $\mathrm{Cl}$ and $\mathrm{A} 1$.

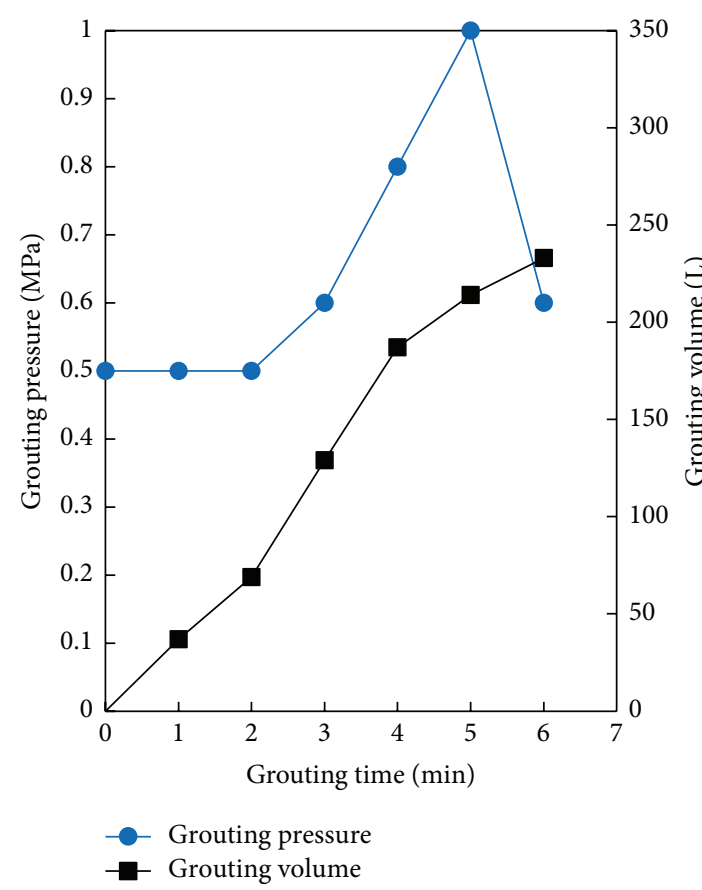

(a) Inject under an increasing grouting pressure

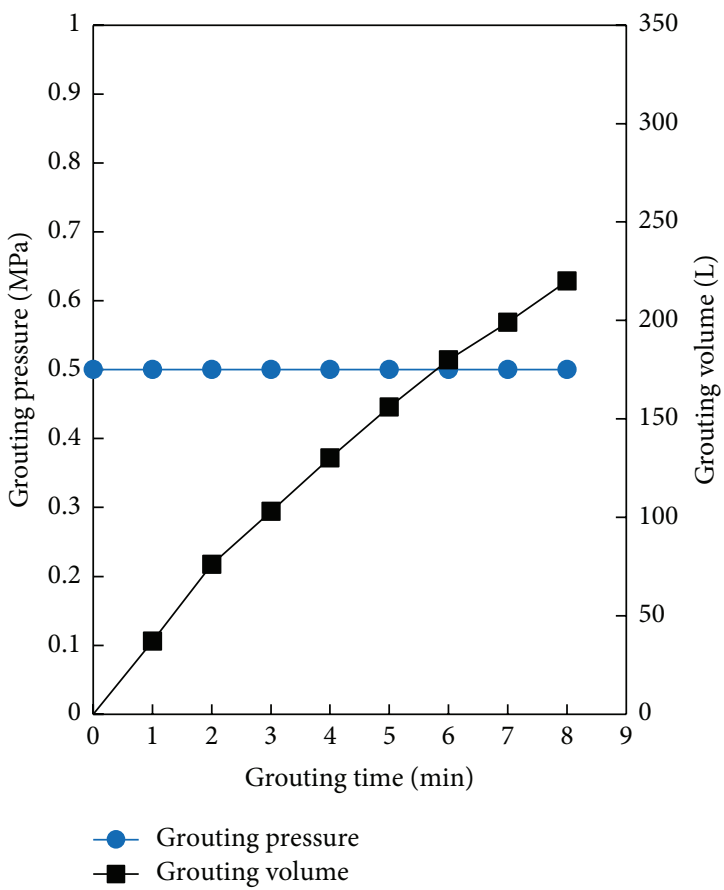

(b) Inject under a constant grouting pressure

FIGURE 11: The typical grouting process of C2 and C11.

gelation time $47.5 \mathrm{~s}$, can be well applied to inject the saturated sandy gravel ground.

(2) The designed ground treatment program: injecting the surrounding holes first and the inner holes next proved to be right. Typical injection process of peripheral group holes demonstrated that this sandy and gravel ground can be easily injected under a low injection pressure and grout leaking occurred 


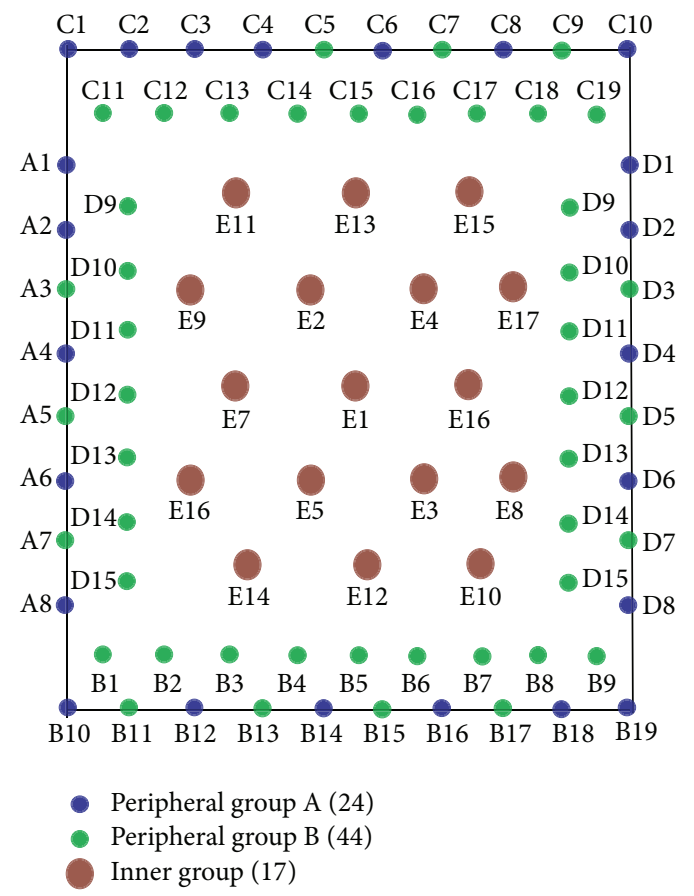

FIGURE 12: Distribution of 3 groups of boreholes.

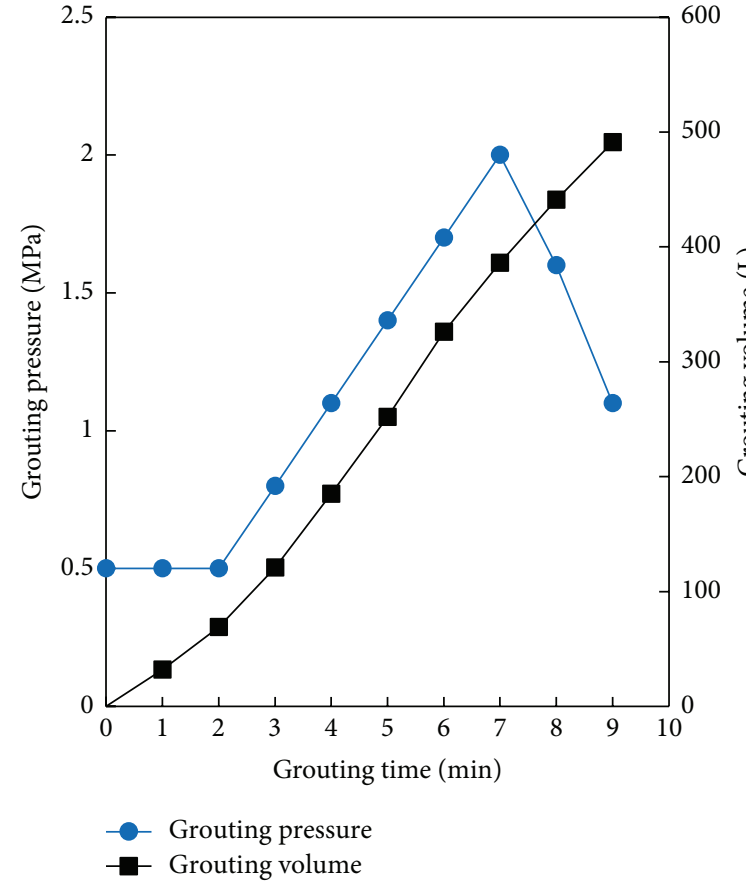

(a) Inject under an increasing grouting pressure

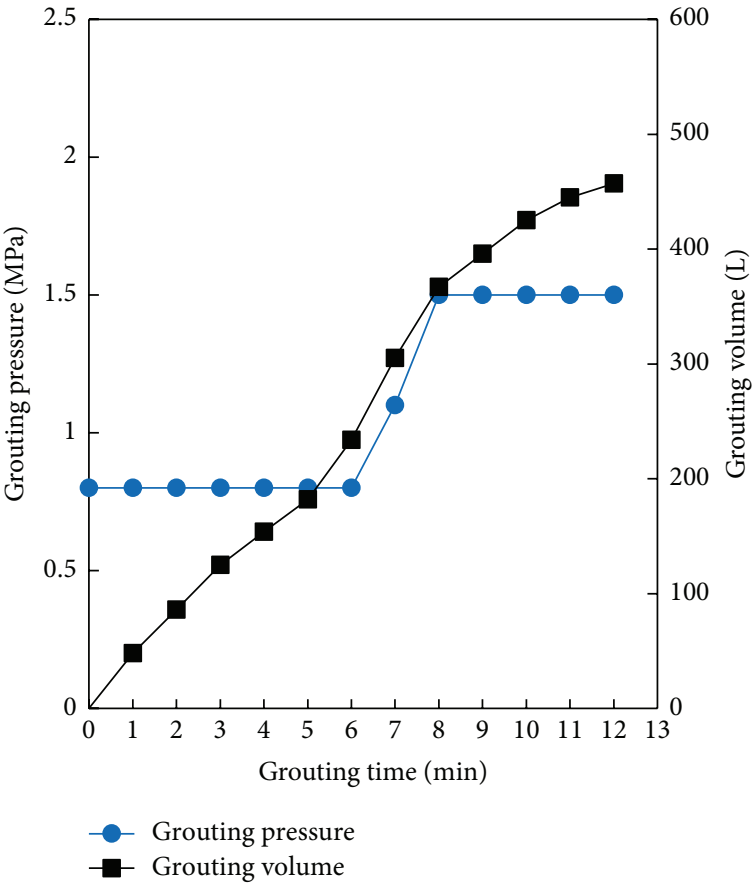

(b) Inject under a constant grouting pressure

FIGURE 13: The typical grouting process of E1.

frequently in the adjacent holes when the injection pressure was increased over $0.8 \mathrm{MPa}$. The holes of inner group were injected later; a high injection pressure was more appropriate considering the grouting curtain had been created. Taking the factors of time saving and effectiveness of grouting into account, the specified injection criteria in this test are as follows: the holes in peripheral group A were injected first at a 


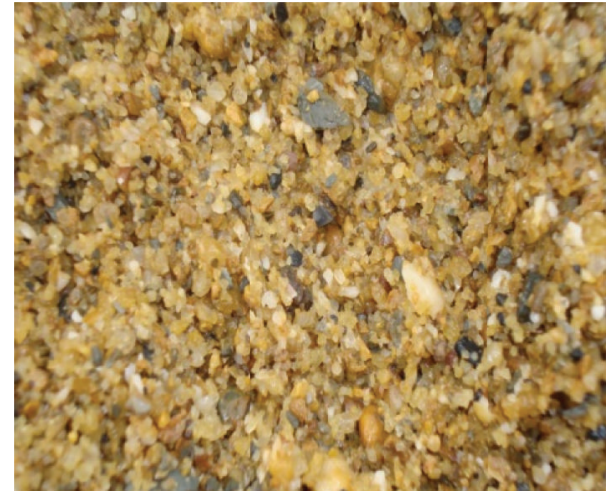

FIGURE 14: Core sample of fine gravel before grouting.

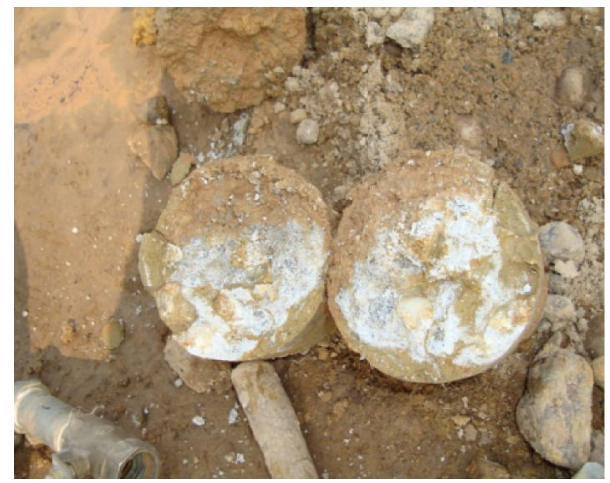

FIGURE 15: Core sample of fine gravel after grouting.

principle of low injection pressure whose value was in the range $0.5 \sim 0.8 \mathrm{MPa}$ and a constant grout volume of $280 \mathrm{~L}$. The holes in peripheral group B were injected at a constant volume of $220 \mathrm{~L}$ or a certain end pressure of $1 \mathrm{MPa}$. The inner group holes were grouted with an increasing grouting pressure and ended at pressure of $2 \mathrm{MPa}$.

(3) Core boring check results indicated that the strata integrity and stability are significantly improved, and the coefficient permeability on completion of grouting trial is lower than $1 \times 10^{-6} \mathrm{~m} / \mathrm{s}$, which could meet the underground construction requirements of waterproofing and subgrade bearing capacity, and the protection dike was in a safe state during grouting.

(4) The empirical formulas chosen to predict the demanded grout volume fit well with the actual situations. The specified injection criteria which contain injection pressure, grout volume, and grout sequence and obtained from the frond holes for three groups contribute to sufficient strength of the entire field. Additionally, these effective injection criteria and control methods will provide valuable references for pregrouting work during the tunnel construction stage.

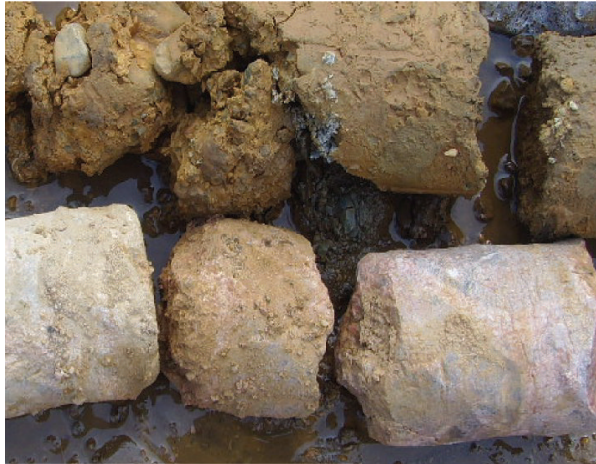

(a)

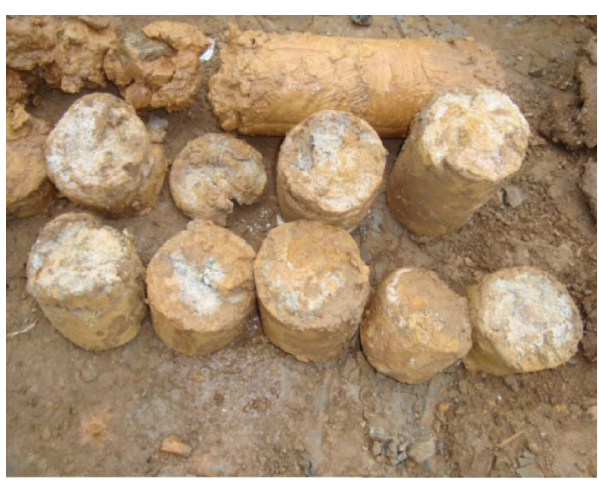

(b)

FIGURE 16: Core sample of sandy gravel after injection.

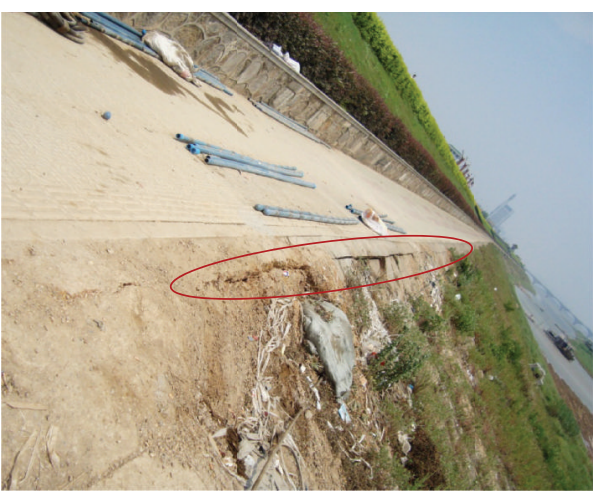

FIGURE 17: The surface uplift in the dike caused by grouting.

\section{Competing Interests}

The authors declare that there are no competing interests regarding the publication of this paper.

\section{Acknowledgments}

This work is financially supported by the Special Fund for Basic Scientific Research of Central Colleges of Changan University (Grant no. 310821165011), the Brainstorm Project on Social Development of Shaanxi Provincial Science and Technology Department (no. 2016SF-412), and the Key 
Industrial Research Project of Shaanxi Provincial Science and Technology Department (Grant no. 2015GY185).

\section{References}

[1] E. D. Graf, "Compaction grouting technique and observations," ASCE, Journal of Soil Mechanics and Foundation Engineering, vol. 95, pp. 1151-1158, 1969.

[2] R. Widmann, "International society for rock mechanics commission on rock grouting," International Journal of Rock Mechanics and Mining Sciences, vol. 33, no. 8, pp. 803-847, 1996.

[3] E. Nonveiller, Grouting Theory and Practice, Elsevier, Amsterdam, The Netherlands, 1989.

[4] J. N. Shirlaw, K. Hayata, G. Berry, and S. Tan, "A review of grouting techniques utilised for bored tunnelling with emphasis on the jet grouting method," Construction and Building Materials, vol. 2, no. 1, pp. 34-41, 1988.

[5] H. Lisa, G. Gunnar, F. Åsa, and N. Tommy, "A statistical grouting decision method based on water pressure tests for the tunnel construction stage-a case study," Tunnelling and Underground Space Technology, vol. 33, no. 1, pp. 54-62, 2013.

[6] J. X. Lai, S. Mao, J. L. Qiu et al., "Investigation progresses and applications of fractional derivative model in geotechnical engineering," Mathematical Problems in Engineering, vol. 2016, Article ID 9183296, 15 pages, 2016.

[7] A. Zolfaghari, A. S. Bidar, M. R. M. Javan, M. Haftani, and A. Mehinrad, "Evaluation of rock mass improvement due to cement grouting by Q-system at Bakhtiary dam site," International Journal of Rock Mechanics and Mining Sciences, vol. 74, pp. 38-44, 2015.

[8] L. Hu, J. Hao, and L. Wang, "Laboratory evaluation of cement treated aggregate containing crushed clay brick," Journal of Traffic and Transportation Engineering (English Edition), vol. 1, no. 5, pp. 371-382, 2014.

[9] J. M. Soler, M. Vuorio, and A. Hautojärvi, "Reactive transport modeling of the interaction between water and a cementitious grout in a fractured rock. Application to ONKALO (Finland)," Applied Geochemistry, vol. 26, no. 7, pp. 1115-1129, 2011.

[10] W. J. Xue, E. Weaver, L. B. Wang, and Y. Wang, "Influence of tyre inflation pressure on measured pavement strain responses and predicted distresses," Road Materials and Pavement Design, vol. 17, no. 2, pp. 328-344, 2016.

[11] L. Hernqvist, Å. Fransson, G. Gustafson, A. Emmelin, M. Eriksson, and H. Stille, "Analyses of the grouting results for a section of the APSE tunnel at Äspö Hard Rock Laboratory," International Journal of Rock Mechanics and Mining Sciences, vol. 46, no. 3, pp. 439-449, 2009.

[12] M. Shimoda and H. Ohmori, "Ultra fine grouting material," in Proceedings of the Conference on Grouting in Geotechnical Engineering, pp. 77-91, ASCE, New Orleans, La, USA, February 1982.

[13] Z.-M. Zhang, J. Zou, J.-Y. He, and H.-Q. Wang, "Laboratory tests on compaction grouting and fracture grouting of clay," Chinese Journal of Geotechnical Engineering, vol. 31, no. 12, pp. 1818-1824, 2009.

[14] H. Güllü, "On the viscous behavior of cement mixtures with clay, sand, lime and bottom ash for jet grouting," Construction and Building Materials, vol. 93, pp. 891-910, 2015.

[15] K. Komiya, K. Soga, H. Akagi, M. R. Jafari, and M. D. Bolton, "Soil consolidation associated with grouting during shield tunnelling in soft clayey ground," Geotechnique, vol. 51, no. 10, pp. 835-846, 2001.
[16] P. Vincent and A. Sadah, "Fabric analyses of some Saudi Arabian pediment gravels," Journal of Arid Environments, vol. 30, no. 4, pp. 371-384, 1995.

[17] J. W. Kim and S. K. Chough, "A gravel lobe deposit in the prodelta of the Doumsan fan delta (Miocene), SE Korea," Sedimentary Geology, vol. 130, no. 3-4, pp. 183-203, 2000.

[18] C. Dano, P.-Y. Hicher, and S. Tailliez, "Engineering properties of grouted sands," Journal of Geotechnical and Geoenvironmental Engineering, vol. 130, no. 3, pp. 328-338, 2004.

[19] Y. Tsukamoto, K. Ishihara, K. Umeda, and T. Enomoto, "Cyclic resistance of clean sand improved by silicate-based permeation grouting," Soils and Foundations, vol. 46, no. 2, pp. 233-245, 2006.

[20] P. Yang, Z.-B. Peng, Y.-Q. Tang, W.-X. Peng, and Z.-M. He, "Penetration grouting reinforcement of sandy gravel," Journal of Central South University of Technology, vol. 15, no. 2, pp. 280284, 2008.

[21] C. R. Yu, Research on grouting influence and Mechanism of shield tunneling in the sand-gravel stratum [Ph.D. thesis], Shanghai Jiao Tong University, Shanghai, China, 2011.

[22] X. Y. Song, "Analysis on deep hole grouting consolidation for tunnels in water-rich sandy gravel stratum," Modern Tunnelling Technology, vol. 48, no. 3, pp. 132-135, 2011.

[23] F. Yong, W. Jun, H. Chuan et al., "Impact of shield tunneling on adjacent spread foundation on sandy cobble strata," Chinese Journal of Modern Transport, vol. 22, no. 4, pp. 244-255, 2014.

[24] A. Bezuijen, R. T. Grotenhuis, A. F. V. Tol, J. W. Bosch, and J. K. Haasnoot, "Analytical model for fracture grouting in sand," Journal of Geotechnical \& Geoenvironmental Engineering, vol. 137, no. 6, pp. 611-620, 2011.

[25] L. Teng and H. Zhang, "Meso-macro analysis of surface settlement characteristics during shield tunneling in sandy cobble ground," Rock and Soil Mechanics, vol. 33, no. 4, pp. 1141-1160, 2012.

[26] J. Cui, S. H. Liu, W. Z. Wang et al., "Experimental study on selection and grouting effect of new grouting materials applied in thick water-rich sandy gravel strata," Tunnel Construction, vol. 35, no. 8, pp. 778-786, 2015.

[27] Shanghai Municipal Engineering Design General Institute, The Plane and Section Blueprint of the Preliminary Design of Xiangjiang River Municipal Road Tunnel in Laodonglu, Shanghai Municipal Engineering Design General Institute, Shanghai, China, 2009.

[28] “Code for design of building foundation,” Tech. Rep. GB500072011, China Architecture and Building Press, Beijing, China, 2011.

[29] Z. B. Peng, Calculation and Construction of Grouting Projection Design, China University of Geosciences Press, Wuhan, China, 1997.

[30] JTG/T F60-2009, Technical Guidelines for Construction of Highway Tunnel, China Communications Press, Beijing, China, 2009.

[31] S.-C. Wu, A.-B. Jin, and Y.-T. Gao, "Studies of sleeve-valve-pipe grouting technique and its effect on soil reinforcement," Rock and Soil Mechanics, vol. 28, no. 7, pp. 1353-1358, 2007.

[32] G. H. Ren, "Case study on consolidation of water-rich cobble/gravel strata in nanning by means of soletanche grouting," Tunnel Construction, vol. 34, no. 12, pp. 1183-1190, 2014.

[33] Y. Luo, J. Chen, W. Xi et al., "Analysis of tunnel displacement accuracy with total station," Measurement, vol. 83, pp. 29-37, 2016. 
[34] J. X. Lai, J. L. Qiu, H. B. Fan et al., "Fiber bragg grating sensorsbased in-situ monitoring and safety assessment of loess tunnel," Journal of Sensors, In press.

[35] E. Nonveiller, Grouting Theory and Practice, Elsevier, Zagreb, Croatia, 1989.

[36] C. A. Anagnostopoulos, "Laboratory study of an injected granular soil with polymer grouts," Tunnelling and Underground Space Technology, vol. 20, no. 6, pp. 525-533, 2005.

[37] J. X. Lai, K. Y. Wang, J. L. Qiu et al., "Vibration response characteristics of the cross tunnel structure," Shock and Vibration, vol. 2016, Article ID 9524206, 16 pages, 2016.

[38] J. J. Cui and X. Q. Cui, Grouting Technology of Tunnel and Undergound Engineering, China Architecture \& Building Press, Beijing, China, 2011.

[39] W. Z. Zhang, Groundwater and Soil Water Dynamics, China Water Resources and Hydropower Publishing House, Beijing, China, 1999.

[40] China Railway Tunnel Group, "Water injecting test report of Xiangjiang river sand and gravel stratum after grouting reinforcement," Research Report, China Railway Tunnel Group, 2013.

[41] A. B. Padura, J. B. Sevilla, J. G. Navarro, E. Y. Bustamante, and E. P. Crego, "Study of the soil consolidation using reinforced jet grouting by geophysical and geotechnical techniques: 'La Normal' building complex (Granada)," Construction and Building Materials, vol. 23, no. 3, pp. 1389-1400, 2009. 

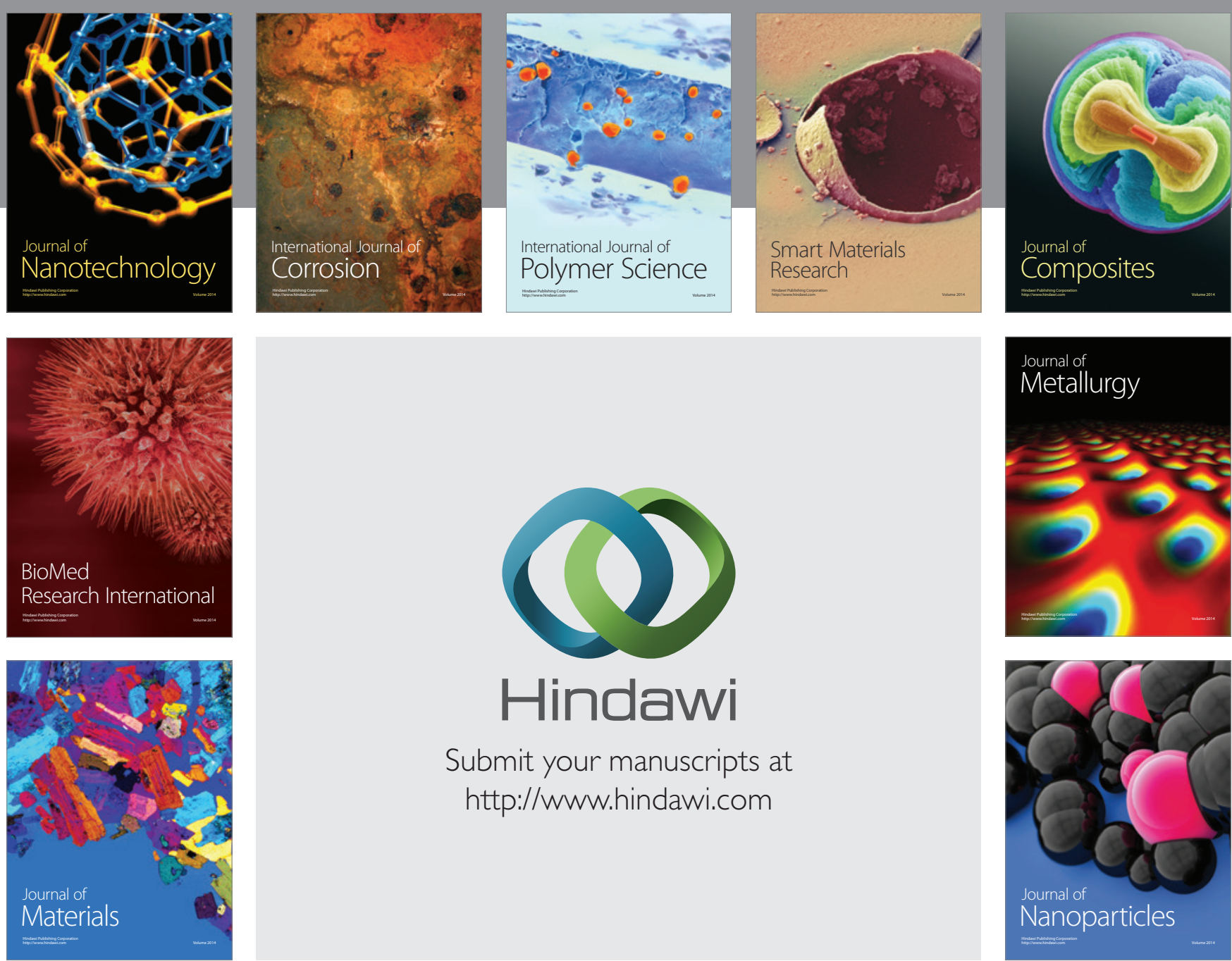

\section{Hindawi}

Submit your manuscripts at

http://www.hindawi.com

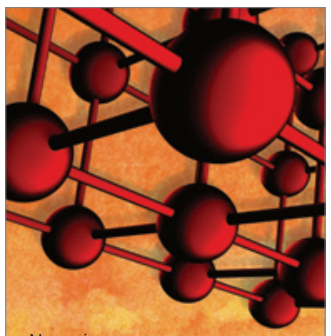

Materials Science and Engineering
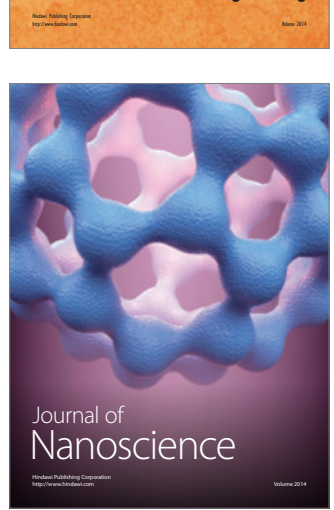
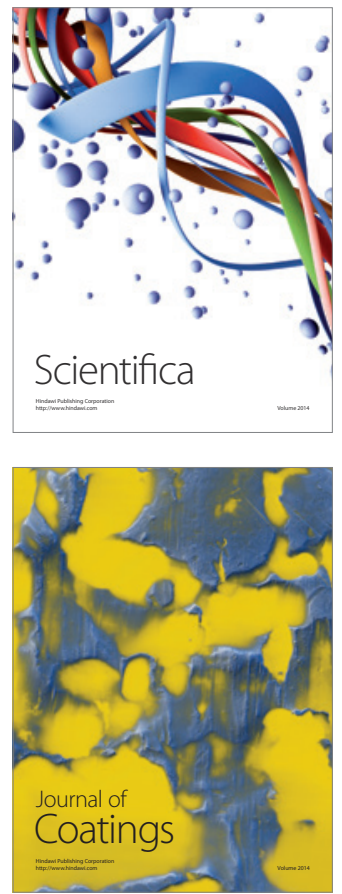
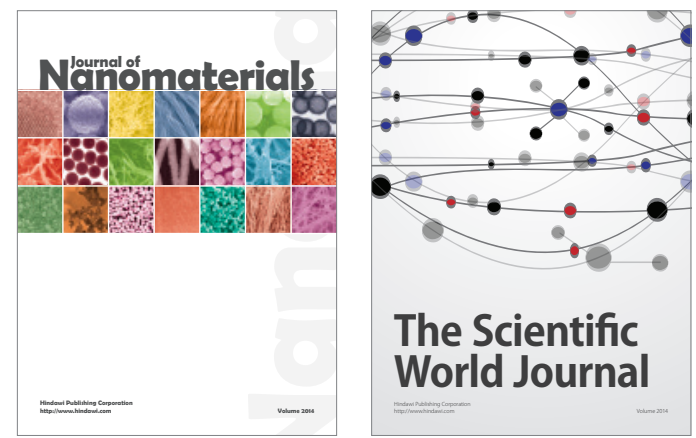

The Scientific World Journal
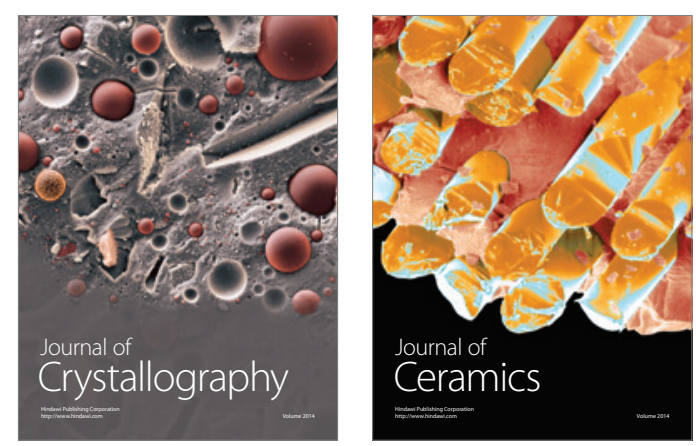
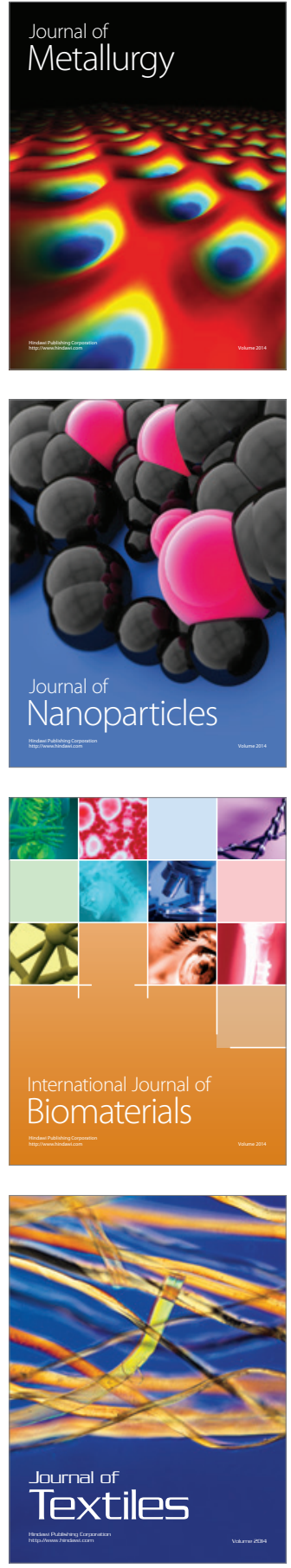